Int. J. Dev. Biol. 51: 549-556 (2007)

doi: $10.1387 / \mathrm{ijdb} .072341 \mathrm{df}$

\title{
Axon guidance in the inner ear
}

\author{
DONNA M. FEKETE* and ANDREA M. CAMPERO \\ Department of Biological Sciences, Purdue University, West Lafayette, IN, USA
}

\begin{abstract}
Statoacoustic ganglion (SAG) neurons send their peripheral processes to navigate into the inner ear sensory organs where they will ultimately become post-synaptic to mature hair cells. During early ear development, neuroblasts delaminate from a restricted region of the ventral otocyst and migrate to form the SAG. The pathfinding mechanisms employed by the processes of SAG neurons as they search for their targets in the periphery are the topic of this review. Multiple lines of evidence exist to support the hypothesis that a combination of cues are working to guide otic axons to their target sensory organs. Some pioneer neurites may retrace their neuronal migratory pathway back to the periphery, yet additional guidance mechanisms likely complement this process. The presence of chemoattractants in the ear is supported by in vitro data showing that the otic epithelium exerts both trophic and tropic effects on the statoacoustic ganglion. The innervation of ectopic hair cells, generated after gene misexpression experiments, is further evidence for chemoattractant involvement in the pathfinding of SAG axons. While the source(s) of chemoattractants in the ear remains unknown, candidate molecules, including neurotrophins, appear to attract otic axons during specific time points in their development. Data also suggest that classical axon repellents such as Semaphorins, Eph/ephrins and Slit/Robos may be involved in the pathfinding of otic axons. Morphogens have recently been implicated in guiding axonal trajectories in many other systems and therefore a role for these molecules in otic axon guidance must also be explored.
\end{abstract}

KEY WORDS: statoacoustic ganglion, chemorepellent, chemoattractant, neurotrophin, semaphorin, slit

\section{Introduction}

The vertebrate inner ear is formed from the otic placode, which is a region of thickened epithelial cells adjacent to the hindbrain. During vertebrate development the otic placode either invaginates or cavitates to create the otocyst. The ventral wall of the otocyst thickens and neuroblasts from this region migrate into the underlying mesenchyme (Adam et al.,1998; Alsina et al., 2004; Rubel and Fritzsch, 2002). These neuroblasts first gather together as the statoacoustic ganglion (SAG). After becoming postmitotic their growth cones emerge from the ganglion to seek out targets among the sensory patches of the inner ear, eventually innervating mature hair cells. This chapter reviews data related to guidance of the peripheral processes (sometimes called dendrites; here called axons or neurites) of the SAG neurons. Excellent earlier reviews on this topic are recommended (Fritzsch et al., 2005b; Fritzsch, 2003, Pauley et al., 2005, Webber and Raz, 2006).

Both chicken and mouse models have been helpful in building a knowledge base in this area. In both species, the initial outgrowth of afferent neurites into the sensory periphery occurs before the SAG neurons have segregated into separate auditory and vestibular ganglia. This is shown schematically in Fig. 1. While the overall innervation of auditory vs. vestibular sensory organs is basically similar in the two species, one of the major distinctions in the bird is the presence of a vestibular sensory organ, the lagena macula, at the distal tip of the cochlear duct. The vestibular neurons that innervate this organ are dispersed along the outer edge of the auditory ganglion rather than aggregated with the other vestibular neurons.

Is the migratory pathway taken by neuroblasts a tract for growth cone guidance to the peripheral sensory organs?

Because the otic neuroblasts project their axons back into the otocyst after migrating away from it, it is conceivable that the same

Abbreviations used in this paper: $\mathrm{BDNF}$, brain-derived neurotrophic factor; E, embryonic day; HH, Hamburger-Hamilton stage; Npn-1, neuropilin-1; NT3, neurotrophin-3; Robo, roundabout; SAG, statoacoustic ganglion; Sema3e, semaphorin $3 \mathrm{e}$. 


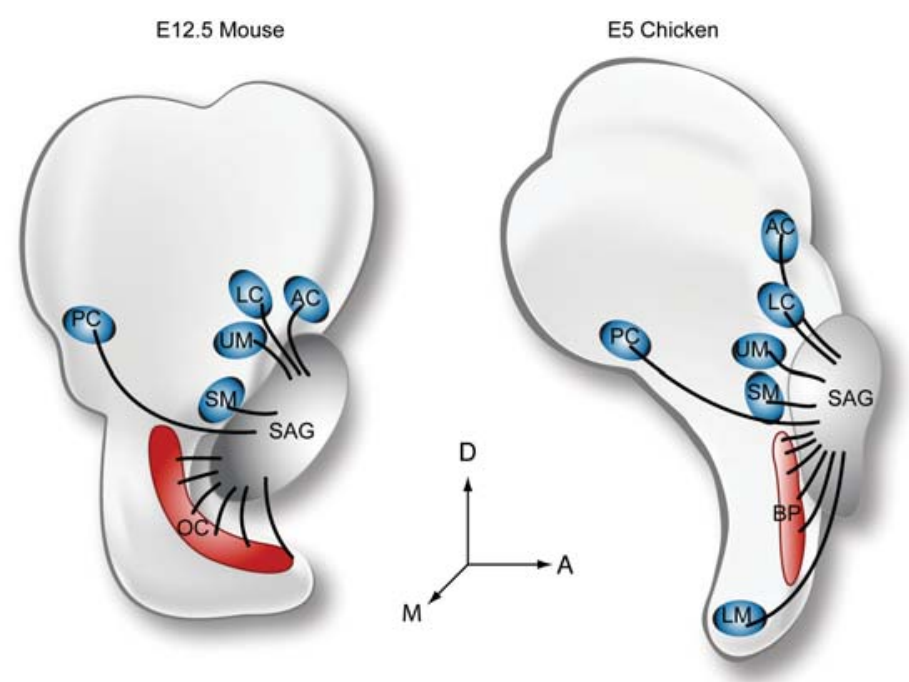

Fig. 1. Axon outgrowth has been studied in both mouse and chicken inner ears, shown schematically at a stage shortly after afferent axons reach their targets. In both species, axons arrive at their targets when the sensory primordia are still in a primitive stage lacking mature hair cells. Although the arrival of axons at the different sensory primordia is not simultaneous, by E12.5 in mouse and E5 in chicken, at least some axons have navigated to each organ. Abbreviations: $A$, anterior; $A C$, anterior crista; $B P$, basilar papilla; $D$, dorsal; $L C$, lateral crista; $L M$, lagena macula; $M$, medial; OC, organ of Corti; $P C$, posterior crista; SM, saccular macula; UM, utricular macula.

pathway could be used for both events. It has even been suggested that the trailing processes of migrating neuroblasts could serve as a substrate for pioneer axons to find their way back into the otocyst (Carney and Silver, 1983), thus eliminating the need for a long-range attractant. Electron microscopy confirms that the neuroblasts and growth cones indeed overlap within the migratory pathway (Carney and Silver, 1983).

Although some pioneer axons travel towards the site of neuroblast delamination, it is difficult to explain how axons could reach all the different sensory targets in the ear through such a 'reversepathfinding' mechanism. This mechanism requires a connection from each sensory primordium to the SAG via a migratory pathway; in other words, each sensory primordium should generate neuroblasts. In birds, the neuroblasts delaminate from a rather restricted sector near the anteroventrolateral pole of the otic cup and otocyst. Yet the prosensory domain has been mapped to a broader region along the entire ventromedial quadrant, at least in chicken (Cole et al., 2000). Thus, it is likely that there is only partial overlap between the original location of the delaminating neuroblasts and the sensory primordia that will become final destinations of their peripheral axons. This prediction is reinforced by lineage data in the chicken showing that neurons of the auditory and vestibular ganglia share common progenitors only with epithelial cells located anteriorly within the otocyst, specifically within or adjacent to the utricular macula (Satoh and Fekete, 2005).

Similarly in the mouse, there appears to be a prolonged release of neuroblasts from or near the two macular primordia based on overlap in the expression of neurotrophins and NeuroD (Fritzsch et al., 2002). More recent evidence confirms that NeuroD-expressing neuroblasts emigrate from areas that will become the utricular macula and the saccular macula (Raft et al., 2007). Several other organs in the mouse arise near the boundary with this neurogenic domain but not within it, including the anterior and lateral crista and at least the proximal portion of the organ of Corti.

In summary, it seems quite possible that projections into many of the sensory organs might be facilitated by pioneer axons that could retrace the neuronal migratory path back to the periphery. However, this strategy is unlikely to benefit those axons heading towards the most far-flung sensory organs, particularly the posterior crista. In this case, the local release of chemoattractants from sensory primordia could serve as long-range beacons for axon guidance. What is the evidence that such attractive cues emanate either from the posterior crista primordium or elsewhere?

\section{Does the target tissue release attractants?}

\section{In vitro assays}

The first evidence of attractants in the inner ear comes from classic in vitro studies which have revealed that the otocyst emits both tropic (promoting directional outgrowth) and trophic (promoting survival) factors. A tropic effect of the sensory epithelium on SAG neurites is suggested by the directed growth of embryonic chick SAG neurites towards otic epithelium in 3dimensional cultures (Hemond and Morest, 1992). Co-cultures of young SAG with young otic epithelium explanted during the time that outgrowth occurs in situ(Hamburger-Hamilton stages 16-21; $\mathrm{HH} 16-21)$ show directed outgrowth in the majority (79\%) of explants. In addition, heterochronic co-cultures were performed with SAG (HH16-30) and otic epithelia (HH16-35) to determine if outgrowth is dependent on the stage of development. Explants of younger SAGs with older otic epithelia show directed outgrowth in $76 \%$ of co-cultures. Similar results were reported for older SAG cultured with younger otic epithelia. Thus, regardless of the stage of development, otic epithelium exerts a tropic effect on SAG neurites. Control co-cultures containing SAG and non-otic epithelia show only weak directed outgrowth in half of the specimens. Surprisingly, co-culture assays reveal that neurons respond directionally to the endolymphatic duct which is a non-sensory, non-innervated otic epithelial structure. This suggests that both sensory and nonsensory otocyst territories can have a tropic effect on SAG neurons.

It can be difficult to dissociate tropic from trophic activity in assays which do not measure directional outgrowth but instead compare the number of axons growing radially from a cultured ganglion in the presence versus the absence of a tissue or purified candidate molecule. Non-directional axon outgrowth assays are further confounded by the fact that some factors, such as neurotrophins, can have both tropic and trophic activity. In a non-directional axon outgrowth assay, cell counts are essential to distinguish between a factor that promotes outgrowth and one that merely appears to do so because more neurons are surviving due to a trophic effect. Not all of the published papers pertaining to the tropic factors for the SAG have quantified neuronal survival. When cell survival has been carefully considered, the data show that the otocyst and mylencephalon each exert a trophic effect on the SAG (Ard et al., 1985). The presence of the central target tissue does not have a significant additive effect on SAG neuron survival when 
co-cultured with the peripheral target, the otocyst.

The developmental timecourse of an otocyst-derived trophic (survival) factor has been investigated in the embryonic chick and shown to differ from the timecourse of the tropic activity. Both embryonic day 4 (E4) otocyst and E4 otocyst-conditioned media have survival effects on SAGs ranging in age from E4-6 to $E 10-13$. However the same is not true for $E 9$ otocysts, when trophic activity appears to be waning (Bianchi and Cohan, 1991). Thus, SAG neurons retain their responsiveness to the diffusible survival factor(s) released from the otocyst, even after neurites have reached their targets and the otocyst developmentally down-regulates such factors. Similar results suggesting that target tissues exert a trophic effect on SAG neurons were reported in the mouse (Van De Water, 1988), although for many of the in vitro studies the quantification of neuronal survival was either indirect (such as percentage of explants with differentiated neurons) or otherwise not well described.

It is notable that the number of neurons surviving in cultures where the target tissue (either otocyst or mylencephalon) and SAG are explanted in one piece is greater than the number of neurons in cultures that separated the target tissue and SAG before explantation (Ard et al., 1985). It seems plausible that local guidance cues, such as those that might be present along axonal projection paths, could influence the ability of neurites to reach their targets to receive trophic support in this sort of assay. When the physical pathway between the neuron and its target is severed, the axons will become more dependent upon soluble factors for pathfinding and/or survival.

\section{Hair cells vs. sensory primordia as the source of chemoattractants}

One mechanism for determining whether sensory organs release attractants for SAG neurons is to ask whether ectopic sensory patches become innervated. In such situations, if axons diverge from their normal trajectories to innervate ectopic hair cells or sensory patches, it may be presumed that they do so under the influence of a chemoattractant acting at a distance. Two recent experiments suggest that ectopic sensory patches have this property during development. In the rodent, forcing the misexpression of Atoh1, a basic helix-loop-helix transcription factor, causes extra hair cells to appear on the neural side of the normal organ of Corti (Zheng and Gao, 2000). These experiments were performed on cultured sensory organs of newborn rats, with Atoh 1 delivered via a viral vector. For the purposes of illustration, however, the outcome is shown schematically on an intact ear in the cartoon of Fig. 2A. At present there are no data to indicate that auditory axons normally sample this region in the search for a target. Thus, the innervation itself is also ectopic and could be explained by the release of a chemotropic factor from the misplaced hair cells. In the chicken, ectopic vestibular sensory patches can be generated within the cochlear duct by forcing the misexpression of Wnt/ $\beta$-catenin signaling (Stevens et al., 2003). At least a small number of such ectopic hair cells appear to receive
Fig. 2. Gain-of-function studies show that inner ear sensory organs can attract statoacoustic (SAG) neurites. (A) In rat, viral gene delivery of Atoh1 to neonatal organ of Corti isolated in culture generates ectopic hair cells. The extra hair cells were located adjacent to the neural side of the organ of Corti in a region called the greater epithelial ridge. Some of these hair cells become innervated, as shown in green (Zheng and Gao, 2000). Although the experiment was conducted in culture, the result is schematically shown as it might appear in an intact ear to ease comparison with results from the chicken. (B) In the chicken cochlea, ectopic sensory patches containing hair cells can be induced by using retroviral vectors to force the misexpression of an activated form of $\beta$-catenin, a downstream signaling component of the canonical Wnt pathway (Stevens et al., 2003). Ectopic vestibular sensory patches can appear along the lateral wall of the cochlear duct. Neurofilament-positive axons can be followed into the misplaced sensory patches (shown in green). (C-E) Histological semi-serial sections showing innervation of ectopic hair cells in the E11 chicken cochlea. (C) A patch of $\beta$-catenin-virus-infected cells (white arrow) on the nonsensory wall of the cochlear duct is identified using an antibody directed against a hemagglutinin tag on the activated $\beta$-catenin protein. Experimental details can be found in Stevens et al., 2003. (D) Nerve branches terminate within the infected patch (arrow and inset); the axon of origin could be traced from the ganglion around the anterior wall of the duct and into the patch. (E) Ectopic hair cells differentiate within the infected patch larrow). The same section shows a normal array of hair cells along the medial wall of the duct; their proximity to the extreme anterior edge of the organ explains why the row appears to be discontinuous. Scale bar for (C-E) is 100 microns; scale bar for the high-power inset of $(E)$ is 20 microns. Abbreviations: BP, basilar papilla; $A G$, acoustic ganglion.
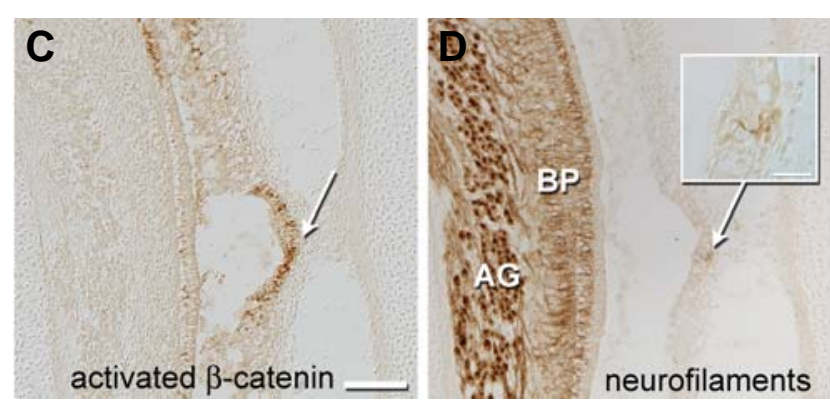

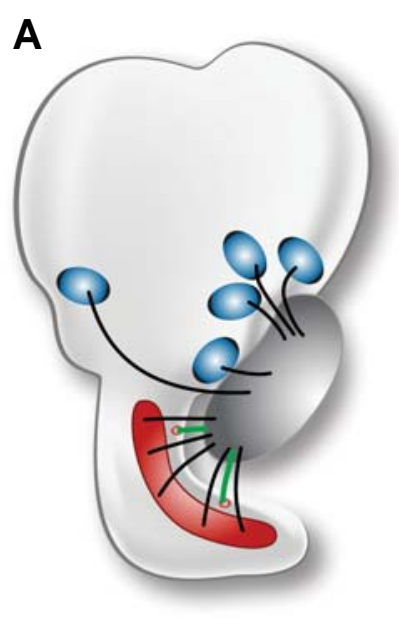

Ectopic Atoh1

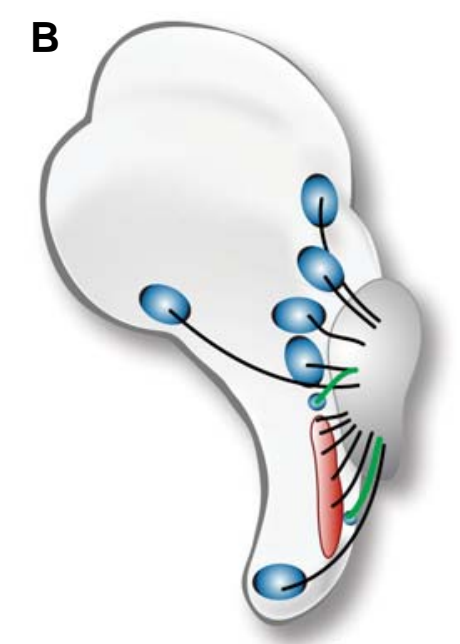

Ectopic activated $\beta$-catenin

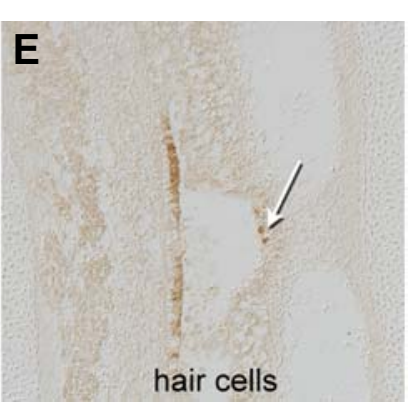


innervation, again via trajectories not seen in normal embryos (Fig. 2 B-E). Although the sensory identity (auditory vs. vestibular) of the neurons supplying the ectopic innervation remains to be determined, the fact that the misplaced sensory patches receive any innervation is indicative of a chemotropin emitted by the sensory primordia.

The results of these gain-of-function experiments raise an important question: If ectopic hair cell innervation reflects chemoattractive activity, does it orginate from hair cells or from the sensory primordia that give rise to them? Based on the normal timing of axon outgrowth, we know that axons arrive in the vicinity of their target areas several days before hair cells differentiate. In fact, axons are typically located just beneath the sensory primordia even before the hair cells are "born", ie., before hair cells undergo their final mitotic division (Whitehead and Morest, 1985). It seems unlikely then, that hair cells could be solely responsible for guiding the axons. Indeed, results from mutant mice in which hair cells fail to differentiate show relatively normal innervation patterns. This is seen in knockout mice for Pou4f3 (previously Brn3c) (Xiang et al., 2003) and Atoh1 (Fritzsch et al., 2005a), shown schematically in Fig. 3. Thus, while the gain-of-function data appear to suggest that hair cells are sufficient to attract neurites, the loss-of-function results indicate that hair cells are not necessary.

But what if the sensory organ itself is missing? The Fgf10null mouse lacks the posterior crista completely and yet an axon bundle that is virtually indistinguishable from wildtype can be followed into the posterior otocyst where the posterior crista would normally be located (Pauley et al., 2003) (Fig. 3). These data support the idea that it is neither the sensory primordia nor the hair cells that are initially responsible for chemoattraction of SAG neurons in normal animals.
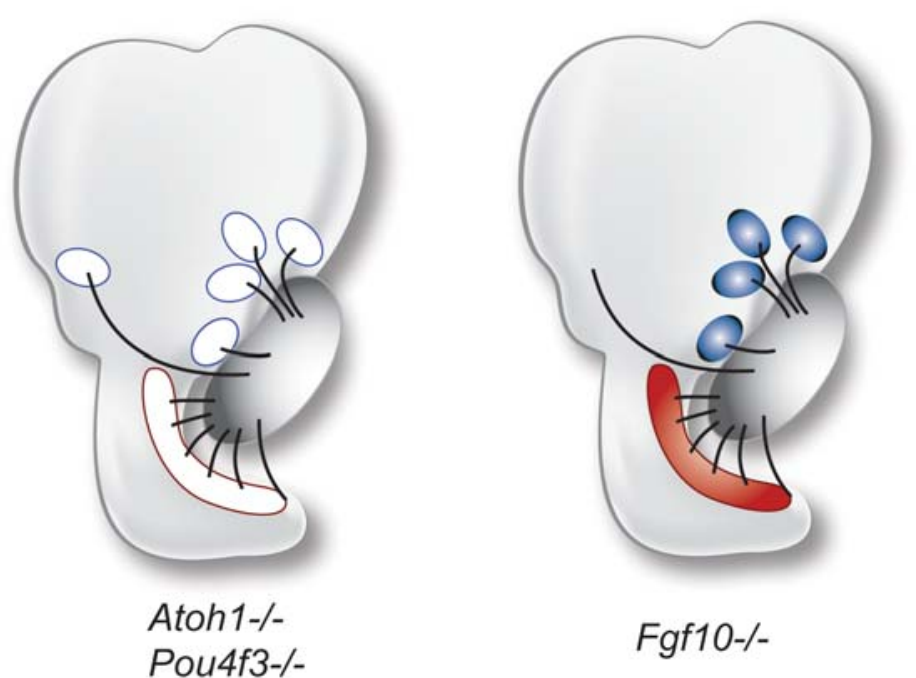

Fig. 3. Neither differentiated hair cells nor sensory primordia are required for statoacoustic (SAG) neurites to follow a normal axon trajectory. Although hair cells fail to develop in Atoh1-null or Pou4f3-null mice, axon outgrow th into the target regions is unaffected. The posterior crista fails to arise in Fgf10-null mice and yet an initial axon tract grows in the direction of the missing organ. Schematics are based on published data (Fritzsch et al., 2005b, Pauley et al., 2003, Xiang et al., 2003).

\section{Neurotrophins as candidates for chemoattraction}

Two neurotrophins, brain-derived neurotrophic factor (BDNF) and neurotrophin-3 (NT-3) are candidate chemotropic factors for guidance of SAG neurons (reviewed in Fritzsch et al., 1999). First, they are expressed early during ear development in areas that receive neurites (Farinas et al., 2001). In the mouse, the earliest neurites appear to project towards the macular primordia at $E 10.5$ and by E11.5 either these or additional projections have reached three BDNF-expression domains that will eventually differentiate into the cristae of the semicircular canals (Figure 4A). The fibers heading towards the cristae must bypass the NT-3-expressing sensory primordia of the maculae. Although the prosensory domains are initially restricted to a single neurotrophin, they all begin to express both neurotrophins within a few days. The cristae primordia continue to express BDNF while becoming flanked by expression of NT-3 in nonsensory territories. The two macular primordia upregulate BDNF in small central domains that may correspond to the striola. At the same time, neurites extend into the NT-3-expressing cochlea, including its BDNF-expressing apical tip (Figure 4B). Knocking out each of the neurotrophins has a profound affect on SAG neuronal survival (Ernfors et al., 1995); this trophic effect has made it problematic to examine their roles as tropic factors. The neuron populations lost after neurotrophin removal vary depending upon which factor is normally present in their target field.

Most if not all SAG neurons express the TrkB and TrkC receptors for BDNF and NT-3, respectively (Farinas et al., 2001), raising the question of why some fibers (like those heading to the cristae) appear selective for one but not the other neurotrophin. Because of the promiscuity of neurotrophin receptor expression, it is possible to ask what happens to axon pathfinding in cases where one neurotrophin is substituted for another. Specifically, will a growth cone be attracted towards the "wrong" target if that target is forced to express the "right" neurotrophin for that particular neuron? If so, a tropic activity is indicated. Such a targeted genetic swap was done by combining a knockout of the $B d n f$ locus with a knock-in of $B d n f$ into the NT-3-null locus, with the genotype designed as NT-3tgBDNF-/ ;BDNF=- (Tessarollo et al., 2004). In this case, the outgrowth of E11.5 axons towards the sensory primordia of the cristae occurs normally, even though the target tissue is expressing neither BDNF nor NT-3 in the mutants (Figure 4C). Surprisingly, the growth cones do not appear to be confused during their navigation past nearby ectopic sources of BDNF. This result suggests that something other than BDNF is responsible for steering the axons toward their correct targets (the presumptive cristae). It is also possible that the BDNF territories are expressing repellents during the time when the axons pass beneath these regions as they circumnavigate the otocyst to reach the cristae. This possibility will be discussed further in the next section. By E12.5, neurites that had been heading towards the posterior crista a day earlier fail to reach their target in the $N T-3^{t g B D N F-}=; B D N F^{-}-$mutant ears, but instead are diverted to other sensory patches, including the basal cochlea, as shown schematically in Figure 4D (green lines). By birth, additional ectopic projections into non-sensory territories are seen. Near the cristae, terminal branches reach beyond the sensory territories, presumably rescued by the replacement of NT-3 with 
BDNF in the non-sensory flanks. An ectopic projection to a haircell-free site between the saccule and utricle is also present (Figure 4D, asterisk); this is proposed to reflect $B d n f$ upregulation by the NT-3 promoter based on a weak expression domain of NT-3 located in a similar position in NT-3-LacZ reporter mice (Tessarollo et al., 2004). The rerouting of axons into ectopic

A $\quad$ E11.5

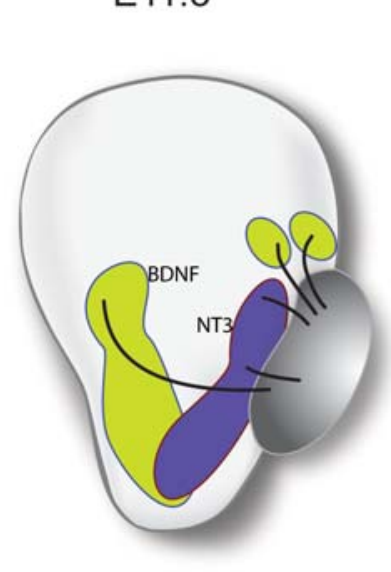

C $\quad \mathrm{E} 11.5$

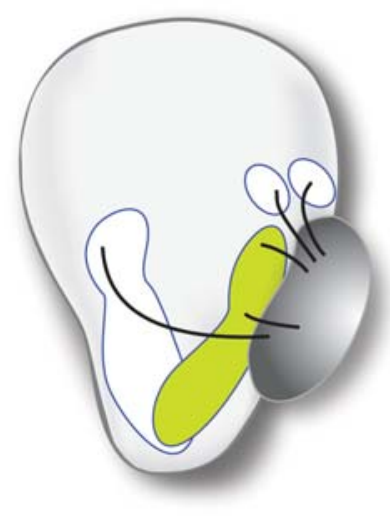

$$
N T-3^{\text {tgBDNF- }} ; B D N F^{-/}
$$

Fig. 4. Evidence for chemoattraction of sensory primordia and brain derived neurotrophic factor (BDNF) during ear development. (A-B) Schematic expression patterns of BDNF and neurotrophin-3 (NT-3) in the otocyst at two developmental stages (based on Farinas et al., 2001). (CD) Results of axon trajectories in transgenic mice that are null at the Bdnf locus and carry a knock-in of Bdnf into the NT-3 locus. (C) Axons initially project to the crista primordia even when they are devoid of the neurotrophin, BDNF, revealing that this cannot be the sole chemoattractant for innervation of the cristae. Furthermore, the axons appear to ignore more proximal sources of BDNF on their way to the cristae. (D) The knock-in allele continues to force ectopic expression of Bdnf at sites normally reserved for NT-3 expression. This leads to aberrant axonal branches and projections (green lines). The asterisk denotes projections into a region that does not contain sensory cells but that is presumed to transiently expresses Bdnf under these conditions. Similarly, axons project aberrantly into the cristae flanks, where BDNF is ectopically expressed in domains normally specific for NT-3. Schematics are based on published data (Tessarollo et al., 2004).
BDNF-expressing territories strongly suggests that either BDNF itself, or something else turned on downstream of it, has an attractive tropic effect on SAG neurons.

\section{Are repellents used to steer axons in the inner ear?}

\section{Semaphorins and neuropilins}

As discussed above, it seems likely that attractive cues direct SAG neurites to their sensory targets. However, repulsive cues can play an equally important role in generating the correct innervation patterns. Data from mutant mice implicate one class of axon repellents, the Semaphorins, in providing a stop signal to growing SAG neurites to prevent them from continuing past the sensory targets to enter into the dorsal otocyst and beyond (Figure 5). Semaphorins are a class of axon repellents that were purified by their ability to collapse growth cones. Class 3 Semaphorin signaling of axon repulsion requires the presence of both a ligand-binding Neuropilin receptor and a signal-transducing subunit, the Plexin co-receptor (reviewed by He et al., 2002). In the inner ear, PlexinA1 and PlexinA2 have been reported to be expressed in developing SAG neurons on E16.5 (Murakami et al., 2001).

To undertake a functional analysis of the Semaphorin-Neuropilin signaling system in axonal pathfinding using targeted mutation of neuropilin-1 (Npn-1; also called Nrp-1), it is necessary to avoid the early embryonic lethalities due to perturbations in VEGF-Neuropilin signaling. To accomplish this, researchers knocked into the Npn1 locus an allele encoding a seven amino-acid substitution in the Npn-1 receptor that prevents it from binding to Class 3 Semaphorins but not to VEGF ligands. Mice homozygous for this allele, called npn-1Sema1-, show navigational errors among their SAG neurons. Specifically, some axons fail to stop when they reach the sensory targets, but continue dorsally to reach the skin (Gu et al., 2003). The origin of these aberrant connections was confirmed by retrograde tracing from the skin back to the vestibular ganglion. Interestingly, the novel otic territory the mutant axons traverse to reach the skin expresses high levels of Semaphorin 3e (Sema3e) transcripts in wildtype mice (Miyazaki et al., 1999). It would appear that the absence of a functional Npn-1 receptor renders the growth cones insensitive to a repulsive Sema3e signal. The central projections of these neurons were apparently unchanged by their altered peripheral connections: at least some of the afferents innervating the skin were shown to terminate in vestibular nuclei of the brainstem (Gu et al., 2003).

\section{Ephs and ephrins}

The ephrins are a large class of membrane-associated proteins that interact through Eph receptor tyrosine-kinases to mediate cell-cell interactions during development, particularly in the nervous system. Unlike most ligand-receptor combinations, signaling between Ephs and ephrins can be bidirectional. In the field of axon guidance, this signaling system was first noted for its role in topographic mapping in the visual system (reviewed in McLaughlin and O'Leary, 2005). Expression gradients of Ephs and ephrins are present when retinal ganglion cells are establishing connections in the tectum. There is considerable experimental evidence to suggest that pathfinding along the nasal-temporal axis relies on repulsive interactions between ephrins and Ephs. The repulsive action of ephrins on neurites is not universal, 


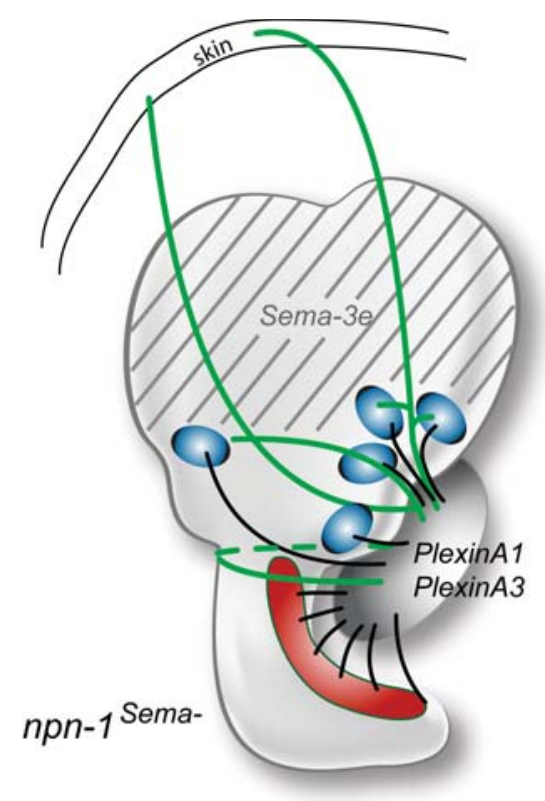

Fig. 5. Evidence for a Semaphorin-mediated stop signal in the dorsal otocyst. One of the class 3 Semaphorin ligands, Sema-3e (formerly SemaH), is expressed in the dorsal part of the mouse otocyst on E10.5 and E11.5 (grey stripes) and in the ampullae, but not the cristae of the semicircular canals at E16.5. Two PlexinA family members, presumed to function as Npn-1 coreceptors, are expressed in the statoacoustic ganglion (SAG) at similar stages. In mice where the Npn-1 receptor has been modified to be insensitive to Sema3, SAG neurites project dorsally beyond their normal targets and fail to stop upon reaching the Sema3 domain (shown in green). Schematics are based on published data (Gu et al., 2003, Miyazaki et al., 1999, Murakami et al., 2001).

however, because Eph-ephrin interactions appear to be attractive in mediating dorsal-ventral retinotectal topography (Holmberg and Frisen, 2002).

In any case, there is interest in determining whether or not Ephs and ephrins are involved in axon guidance in the inner ear or in its central projections (reviewed by Cramer, 2005, Webber and Raz, 2006). At embryonic stages of axon outgrowth, spiral (auditory) ganglion neurites travel between two walls of EphA4producing cells while en route to the primordium of the organ of Corti in the mouse (van Heumen et al., 2000). Curiously, the precise pattern of EphA4 expression seen in mouse is not conserved in embryonic gerbils or guinea pigs: in the latter two species EphA4 is expressed in spiral ganglion neurons but not in the fibroblasts lining their projection pathway (Bianchi and Gale, 1998, van Heumen et al., 2000). In mouse, EphB2 and EphA4 both exert repulsive effects on postnatal day 3-5 spiral ganglion axons in vitro (Bianchi and Gray, 2002, Brors et al., 2003). It is therefore tempting to extrapolate these functional results from the postnatal period to the embryonic stages to conclude that Ephephrin interactions indeed keep spiral ganglion neurites on a straight-and-narrow path as they navigate towards the sensory periphery. The repulsive action of EphA4 is mitigated by antibodies to ephrin-B2 and -B3 (Brors et al., 2003). While the spiral ganglion neurons of embryonic and/or postnatal mice indeed express these two ephrins, they also express other ephrins and Eph receptors, further complicating the picture (Bianchi and Gale, 1998, Rinkwitz-Brandt et al., 1996, van Heumen et al., 2000).
Perhaps the most provocative in terms of establishing a tonotopic map is the observation of opposing basal-apical gradients of EphA4 and EphB2 immunoreactivity in neurites projecting along the developing cochlea of the bird (Siddiqui and Cramer, 2005). Related ephrin gradients in the peripheral targets of the auditory neurons have not yet been reported.

Mice mutant for EphB show transient defects in their efferent vestibular projections (Cowan et al., 2000). Because cochlear efferents use afferents for pathfinding (Fritzsch et al., 1998), defective efferent innervation raises the possibility that efferents interact with afferents through Eph-ephrin signaling. Because there are many possible interactions between the members of the Eph and ephrin families, redundancy may be masking the role of these molecules in peripheral axon guidance in the inner ear.

\section{Slits and robos}

The Slit/Robo signaling family of axonal repellents can affect axon guidance, axon branching, axon fasciculation and cell migration in a variety of vertebrate and invertebrate systems (reviewed in Wong et al., 2002). Slit, a secreted ligand, was first identified in Drosophilaas a chemorepellent expressed by midline cells in the central nervous system. Roundabout (Robo) proteins, conserved members of the Ig superfamily, are transmembrane receptors for Slit.

Currently, two Robo homologues and three Slithomologues have been identified in the chick (Bashaw and Goodman, 1999, Li et al., 1999, Vargesson et al., 2001). Whole mount in situ hybridizations show expression of Slit2 and Slit3 in the chick otocyst (Holmes and Niswander, 2001), although detailed expression in the ear was not reported. We have preliminary data in the chicken showing that Robo2 is expressed in the cells of the SAG while both Robo1 and Robo2 are present in the sensory epithelium during peripheral process pathfinding. We also observe all three Slit transcripts in the medial otocyst at the time axons begin to emerge from the SAG (Campero and Fekete, 2007). In the mouse this region would approximately correspond to the large NT-3 domain in the E10.5-E11.5 vestibule (shown schematically in Figure 4A). If we extrapolate the findings across species, we can speculate that the coincidental presence of Slit in the NT-3 domain serves to repel navigating axons that might otherwise respond to the neurotrophin, thus explaining why axons initially bypass this prosensory epithelium on their way towards the more distant cristae. It might then be necessary for axons to become unresponsive to Slits and/or to upregulate TrkC receptor to enable them to enter this prosensory domain and innervate the utricular and saccular maculae.

Preliminary data show expression of Robo1 protein in the developing spiral ganglion of the mouse (Hackett et al., 2007). Thus the ligands and receptors are present in appropriate times and places to influence axon pathfinding during otogenesis. Functional studies are now needed to further explore this possibility.

\section{Future Directions}

\section{Morphogens as axon guidance candidates}

Some new players in the arena of axon guidance have come to the fore in recent years. In vertebrates these include Wnts, BMPs and Sonic hedgehog (Shh), which have traditionally been 
viewed as morphogens that function through concentration gradients to control pattern formation and cell fate specification in developing embryos (Charron and Tessier-Lavigne, 2005). We consider the Wnts in the vertebrate nervous system by way of example. Yimin Zou's group has shown that weak gradients of Wnt ligands are present along the anterior-posterior axis of the spinal cord (Liu et al., 2005, Lyuksyutova et al., 2003). Longitudinal axons traveling either up or down the spinal cord appear to use these gradients to provide directional information during axon outgrowth. Both attractive and repulsive interactions with Wnt ligands were reported, depending upon the particular pathway and its combination of Wnt ligands and Frizzled or Ryk receptors (Schmitt et al., 2006).

This new category of morphogens as potential guidance molecules will need to be explored in the context of SAG neurite outgrowth. Our lab has preliminary data showing that there are transcripts for many different Wnt ligands, Wnt receptors and Wnt inhibitors expressed in the embryonic chicken otocyst, the SAG or the nerve during the key stages of neurite outgrowth (Sienknecht and Fekete, unpublished observations). Mouse mutants have been used to show that both Wnts and Shh are required for otic morphogenesis, particularly in the context of dorsal-ventral ligand gradients originating from tissues outside the ear (Bok et al., 2007, Riccomagno et al., 2002, Riccomagno et al., 2005). The presumed concentration gradients of Wht (high dorsally) and Shh (high ventrally) raise the possibility that SAG neurons may subsquently use the same gradients to establish tonotopic projections along the cochlea or for guiding vestibular afferents. BMP ligands have long been known to be present in otic sensory primordia from their earliest appearance; perhaps we need to consider their potential as chemoattractants directing SAG axons toward these target sites. What is now needed are functional studies designed to dissociate the known morphogenetic impact of Wnts, BMPs and Shh on the inner ear from their possible effects on axon guidance.

\section{Guidance cues for central navigation}

Research on axon guidance in the inner ear has some obvious clinical implications. Therapeutic approaches for hair cell regeneration presume that the neurites will navigate to the new hair cells to establish functional connections. Thus it becomes important to identify both attractants and repellents for this class of neurons and to ascertain if any of these are still present or perhaps upregulated during hair cell regeneration. Researchers are also interested in the preservation or replacement of SAG neurons that degenerate in deafened individuals, either as a secondary consequence of the loss of survival factors when hair cells die, or because the neuronal loss is a more primary contributor to deafness. In either case, biologically-based therapeutics aiming to restore neuron numbers will require that the replacement neurons make appropriate connections both centrally and peripherally (Rubel and Fritzsch, 2002). Research on the establishment and maintenance of central projections is lagging behind that of the peripheral processes, although this is now being explored at the molecular level (Cramer, 2005) and we can look forward to rapid progress in this field.

\section{Acknowledgements}

We thank Bernd Fritzsch, Andy Groves and Yael Raz for sharing data or manuscripts in advance of publication. We would also like to thank
Rodney McPhail for the graphics. This work was supported by NIH grant DC002756.

\section{References}

ARD, M.D., MOREST, D.K. and HAUGER, S.H. (1985). Trophic interactions between the cochleovestibular ganglion of the chick embryo and its synaptic targets in culture. Neuroscience 16: 151-70.

BASHAW, G.J. and GOODMAN, C.S. (1999). Chimeric axon guidance receptors the cytoplasmic domains of slit and netrin receptors specify attraction versus repulsion. Cel/97: 917-26.

BIANCHI, L.M. and COHAN, C.S. (1991). Developmental regulation of a neuritepromoting factor influencing statoacoustic neurons. Brain Research. Developmental Brain Research 64: 167-74.

BIANCHI, L.M. and GALE, N.W. (1998). Distribution of Eph-related molecules in the developing and mature cochlea. Hearing Research 117: 161-72.

BIANCHI, L.M. and GRAY, N.A. (2002). EphB receptors influence growth of ephrinB1-positive statoacoustic nerve fibers. European Journal of Neuroscience 16: 1499-506.

BOK, J., DOLSON, D.K., HILL, P., RUTHER, U., EPSTEIN, D.J. and WU, D.K (2007). Opposing gradients of Gli repressor and activators mediate Shh signaling along the dorsoventral axis of the inner ear. Development 134: 1713 22.

BRORS, D., BODMER, D., PAK, K., ALETSEE, C., SCHAFERS, M., DAZERT, S. and RYAN, A.F. (2003). EphA4 provides repulsive signals to developing cochlear ganglion neurites mediated through ephrin-B2 and -B3. Journal of Comparative Neurology 462: 90-100.

CAMPERO, A.M. and FEKETE, D.M. (2007). Expression of Slits and robos during chick inner ear development suggests dual roles in axon guidance and in epithelial boundaries. Assoc. Res. Otolaryngol. Abs. page 192.

CARNEY, P.R. and SILVER, J. (1983). Studies on cell migration and axon guidance in the developing distal auditory system of the mouse. Journal of Comparative Neurology 215: 359-369.

CHARRON, F. and TESSIER-LAVIGNE, M. (2005). Novel brain wiring functions for classical morphogens: a role as graded positional cues in axon guidance. Development 132: 2251-62.

COLE, L.K., LE ROUX, I., NUNES, F., LAUFER, E., LEWIS, J. and WU, D.K. (2000) Sensory organ generation in the chicken inner ear: contributions of bone morphogenetic protein 4, serrate1 and lunatic fringe. Journal of Comparative Neurology 424: 509-20.

COWAN, C.A., YOKOYAMA, N., BIANCHI, L.M., HENKEMEYER, M. and FRITZSCH, B. (2000). EphB2 guides axons at the midline and is necessary for normal vestibular function. Neuron 26: 417-30.

CRAMER, K.S. (2005). Eph proteins and the assembly of auditory circuits. Hearing Research 206: 42-51.

ERNFORS, P., VAN DE WATER, T., LORING, J. and JAENISCH, R. (1995). Complementary roles of BDNF and NT-3 in vestibular and auditory development. Neuron 14: 1153-1164.

FARINAS, I., JONES, K.R., TESSAROLLO, L., VIGERS, A.J., HUANG, E., KIRSTEIN, M., DE CAPRONA, D.C., COPPOLA, V., BACKUS, C., REICHARDT, L.F. et al. (2001). Spatial shaping of cochlear innervation by temporally regulated neurotrophin expression. Journal of Neuroscience $21: 6170-80$

FRITZSCH, B. (2003). Development of inner ear afferent connections: forming primary neurons and connecting them to the developing sensory epithelia. Brain Research Bulletin 60: 423-33.

FRITZSCH, B., BARBACID, M. and SILOS-SANTIAGO, I. (1998). The combined effects of trkBand trkC mutations on the innervation of the inner ear. Int. J. Dev. Neuroscience.

FRITZSCH, B., BEISEL, K.W., JONES, K., FARINAS, I., MAKLAD, A., LEE, J. and REICHARDT, L.F. (2002). Development and evolution of inner ear sensory epithelia and their innervation. Journal of Neurobiology 53: 143-56.

FRITZSCH, B., MATEI, V.A., NICHOLS, D.H., BERMINGHAM, N., JONES, K. BEISEL, K.W. and WANG, V.Y. (2005a). Atoh1 null mice show directed afferent fiber growth to undifferentiated ear sensory epithelia followed by incomplete fiber retention. Developmental Dynamics 233: 570-83. 
FRITZSCH, B., PAULEY, S., MATEI, V., KATZ, D.M., XIANG, M. and TESSAROLLO, L. (2005b). Mutant mice reveal the molecular and cellular basis for specific sensory connections to inner ear epithelia and primary nuclei of the brain. Hearing Research 206: 52-63.

FRITZSCH, B., PIRVOLA, U. and YLIKOSKI, J. (1999). Making and breaking the innervation of the ear: neurotrophic support during ear development and its clinical implications. Cell and Tissue Research 295: 369-82.

GU, C., RODRIGUEZ, E.R., REIMERT, D.V., SHU, T., FRITZSCH, B., RICHARDS, L.J., KOLODKIN, A.L. and GINTY, D.D. (2003). Neuropilin-1 conveys semaphorin and VEGF signaling during neural and cardiovascular development. Dev Ce//5: 45-57.

HE, Z., WANG, K.C., KOPRIVICA, V., MING, G. and SONG, H.J. (2002). Knowing how to navigate: mechanisms of semaphorin signaling in the nervous system. SCi STKE2002 (119), re1. [DOI: 10.1126/stke.2002.119.re1].

HACKETT, L., GAO, W. and RAZ, Y. (2007). Robo protein is expressed in the developing spiral ganglion during neurite outgrowth. Assoc. Res. Otolaryngol. Abs. page 192.

HEMOND, S.G. and MOREST, D.K. (1992). Tropic effects of otic epithelium on cochleo-vestibular ganglion fiber growth in vitro. The Anatomical Record232: 273-284.

HOLMBERG, J. and FRISEN, J. (2002). Ephrins are not only unattractive. Trends in Neurosciences 25: 239-43.

HOLMES, G. and NISWANDER, L. (2001). Expression of slit-2 and slit-3 during chick development. Developmental Dynamics 222: 301-7.

LI, H.S., CHEN, J.H., WU, W., FAGALY, T., ZHOU, L., YUAN, W., DUPUIS, S., JIANG, Z.H., NASH, W., GICK, C. et al. (1999). Vertebrate slit, a secreted ligand for the transmembrane protein roundabout, is a repellent for olfactory bulb axons. Cel/96: 807-18

LIU, Y., SHI, J., LU, C.C., WANG, Z.B., LYUKSYUTOVA, A.I., SONG, X.J. and ZOU, Y. (2005). Ryk-mediated Wnt repulsion regulates posterior-directed growth of corticospinal tract. Nat Neurosci 8: 1151-9.

LYUKSYUTOVA, A.I., LU, C.C., MILANESIO, N., KING, L.A., GUO, N., WANG, Y., NATHANS, J., TESSIER-LAVIGNE, M. and ZOU, Y. (2003). Anterior-posterior guidance of commissural axons by Wnt-frizzled signaling. Science 302: 19848.

MCLAUGHLIN, T. and O'LEARY, D.D. (2005). Molecular gradients and development of retinotopic maps. Annual Review of Neuroscience 28: 327-55.

MIYAZAKI, N., FURUYAMA, T., TAKEDA, N., INOUE, T., KUBO, T. and INAGAKI, S. (1999). Expression of mouse semaphorin $\mathrm{H}$ mRNA in the inner ear of mouse fetuses. Neuroscience Letters 261: 127-9.

MURAKAMI, Y., SUTO, F., SHIMIZU, M., SHINODA, T., KAMEYAMA, T. and FUJISAWA, H. (2001). Differential expression of plexin-A subfamily members in the mouse nervous system. Developmental Dynamics 220: 246-58.

PAULEY, S., MATEI, V., BEISEL, K. and FRITZSCH, B. (2005). Wiring the ear to the brain: the molecular basis of neurosensory development, differentiation and survival. In Development of the Inner Ear, vol. 26 (ed. KELLEY, M. W.WU, D. K.POPPER, A. N. and FAY, R. R.). Spring, New York, NY, pp.85-121.

PAULEY, S., WRIGHT, T.J., PIRVOLA, U., ORNITZ, D., BEISEL, K. and FRITZSCH, B. (2003). Expression and function of FGF10 in mammalian inner ear development. Developmental Dynamics 227: 203-15.

RAFT, S., QUINONES, H., KOUNDAKJIAN, E., JOHNSON, J., GOODRICH, L.V., SEGIL, N. and GROVES, A.K. (2007). Interdependent regulaton of Ngn1 and
Math1 controls cell fate during inner ear development. Assoc. Res. Otolaryngol. Abs.107.

RICCOMAGNO, M.M., MARTINU, L., MULHEISEN, M., WU, D.K. and EPSTEIN, D.J. (2002). Specification of the mammalian cochlea is dependent on Sonic hedgehog. Genes and Development 16: 2365-78.

RICCOMAGNO, M.M., TAKADA, S. and EPSTEIN, D.J. (2005). Wnt-dependent regulation of inner ear morphogenesis is balanced by the opposing and supporting roles of Shh. Genes and Development 19: 1612-23.

RINKWITZ-BRANDT, S., ARNOLD, H.H. and BOBER, E. (1996). Regionalized expression of Nkx5-1, Nkx5-2, Pax2 and sek genes during mouse inner ear development. Hearing Research 99: 129-38.

RUBEL, E.W. and FRITZSCH, B. (2002). Auditory system development: primary auditory neurons and their targets. Annual Review of Neuroscience25: 51-101.

SATOH, T. and FEKETE, D.M. (2005). Clonal analysis of the relationships between mechanosensory cells and the neurons that innervate them in the chicken ear. Development 132: 1687-97.

SCHMITT, A.M., SHI, J., WOLF, A.M., LU, C.C., KING, L.A. and ZOU, Y. (2006). Wnt-Ryk signalling mediates medial-lateral retinotectal topographic mapping. Nature 439: 31-7.

SIDDIQUI, S.A. and CRAMER, K.S. (2005). Differential expression of Eph receptors and ephrins in the cochlear ganglion and eighth cranial nerve of the chick embryo. Journal of Comparative Neurology 482: 309-19.

STEVENS, C.B., DAVIES, A.L., BATTISTA, S., LEWIS, J.H. and FEKETE, D.M. (2003). Forced activation of Wnt signaling alters morphogenesis and sensory organ identity in the chicken inner ear. Developmental Biology 261: 149-64.

TESSAROLLO, L., COPPOLA, V. and FRITZSCH, B. (2004). NT-3 replacement with brain-derived neurotrophic factor redirects vestibular nerve fibers to the cochlea. Journal of Neuroscience 24: 2575-84

VAN DE WATER, T.R. (1988). Tissue interactions and cell differentiation: neuronesensory cell interaction during otic development. Development 103 supplement: 185-193.

VAN HEUMEN, W.R., CLAXTON, C. and PICKLES, J.O. (2000). Expression of EphA4 in developing inner ears of the mouse and guinea pig. Hearing Research 139: $42-50$.

VARGESSON, N., LURIA, V., MESSINA, I., ERSKINE, L. and LAUFER, E. (2001). Expression patterns of Slit and Robo family members during vertebrate limb development. Mechanisms of Development 106: 175-80.

WEBBER, A. and RAZ, Y. (2006). Axon guidance cues in auditory development. Anat Rec A Discov Mol Cell Evol Biol288: 390-6.

WHITEHEAD, M.C. and MOREST, D.K. (1985). The development of innervation patterns in the avian cochlea. Neuroscience 14: 255-276.

WONG, K., PARK, H.T., WU, J.Y. and RAO, Y. (2002). Slit proteins: molecular guidance cues for cells ranging from neurons to leukocytes. Current Opinion in Genetics and Development 12: 583-91.

XIANG, M., MAKLAD, A., PIRVOLA, U. and FRITZSCH, B. (2003). Brn3c null mutant mice show long-term, incomplete retention of some afferent inner ear innervation. BMC Neurosci 4: 2

ZHENG, J.L. and GAO, W.Q. (2000). Overexpression of Math1 induces robust production of extra hair cells in postnatal rat inner ears. Nat Neurosci3: 580-6.

Published Online: 20th July 2007 


\section{Related, previously published Int. J. Dev. Biol. articles}

See our Special Issue Ear Development edited by Fernando Giraldez and Bernd Fritzsch at: http://www.ijdb.ehu.es/web/contents.php?vol=51\&issue=6-7

\section{Analysis of Netrin 1 receptors during inner ear development}

Tanja Matilainen, Maarja Haugas, Jordan A. Kreidberg and Marjo Salminen

Int. J. Dev. Biol. (2007) 51: 409-414

Cell proliferation during the early compartmentalization of the Xenopus laevis inner ear Quincy A. Quick and Elba E. Serrano

Int. J. Dev. Biol. (2007) 51: 201-210

Retinal ganglion cells: dying to survive

Marc B. Guerin, Declan P. McKernan, Colm J. O'Brien and Thomas G. Cotter

Int. J. Dev. Biol. (2006) 50: 665-674

Neurotrophic regulation of retinal ganglion cell synaptic connectivity: from axons and dendrites to synapses Susana Cohen-Cory and Barbara Lom

Int. J. Dev. Biol. (2004) 48: 947-956

Multiple axon guidance cues establish the olfactory topographic map: how do these cues interact? James A St John, Heidi J Clarris and Brian Key

Int. J. Dev. Biol. (2002) 46: 639-647

Axon guidance receptors direct growth cone pathfinding: rivalry at the leading edge. Helen M Cooper

Int. J. Dev. Biol. (2002) 46: 621-631 